\section{Overexpression of lung resistance-related protein and P-glycoprotein and response to induction chemotherapy in acute myelogenous leukemia}

\author{
Kazue Tsuji, ${ }^{1}$ Yan-Hua Wang, ${ }^{1}$ \\ Minoko Takanashi, ${ }^{2}$ Tsuyoshi Odajima, ${ }^{3}$ \\ Gabriel. A. Lee, ${ }^{3}$ Hiroki Sugimori, ${ }^{3}$ \\ Toshiko Motoji \\ 1'Department of Hematology, Tokyo \\ Women's Medical University; \\ 2Japanese Red Cross Tokyo Blood Center; \\ ${ }^{3}$ Graduate School of Sports and Health \\ Sciences, Department of Preventive \\ Medicine, Daito Bunka University, Tokyo \\ Japan
}

\section{Abstract}

Lung resistance-related protein (LRP) and P-glycoprotein (P-gp) are associated with multidrug resistance. P-gp overexpression reduces intracellular anticancer drug concentrations and is correlated with low remission rates. However, whether the presence of LRP influences the response to induction chemotherapy remains controversial. Therefore, we investigated the relationship of LRP and P-gp overexpression with the response to induction chemotherapy. Univariate analysis revealed that there was a significant difference between complete remission rates for acute myelogenous leukemia patients depending on their blast cell expressions, between LRP positive versus negative, $\mathrm{P}$-gp positive versus negative, and LRP/P-gp double positive versus other groups. Crude odds ratios (ORs) for complete remission were $0.390,0.360$, and 0.307 for LRP positive, for P-gp positive, and LRP/Pgp double positive patients, respectively. After controlling the confounding variables by stepwise multivariate logistical regression analysis, the presence of LRP/P-gp double positivity and P-gp positivity were found to be independent prognostic factors; adjusted ORs were 0.233 and 0.393 , respectively. Furthermore, the monoclonal antibody against LRP significantly increased daunorubicin acumulation $(P=0.004)$ in the nuclei of leukemic blast cells with LRP positivity in more than $10 \%$ of the cells. An LRP reversing agent, PAK-104P, was found to increase the daunorubicin content with marginal significance $(\mathrm{P}=0.060)$. The present results suggest that not only the presence of P-gp, but also LRP in leukemic blast cells is a risk factor for resistance to induction chemotherapy. Inhibiting LRP function, simi- lar to the inhibition of P-gp function, will be necessary to improve the effectiveness of induction chemotherapy.

\section{Introduction}

Although the clinical outcome of acute myelogenous leukemia (AML) has improved with advancements in chemotherapy, treatment is still problematic. One of the major challenges for treatment is the resistance of leukemia blast cells to anticancer drugs. The most wellknown proteins associated with multidrug resistance to anticancer drugs are P-glycoprotein (P-gp), lung resistance-related protein (LRP), and multidrug resistance-associated protein. P-gp overproduction reduces intracellular drug concentrations by binding to the drugs and acting as an adenosine triphosphate-dependent efflux pump. ${ }^{1}$ Several studies, including ours, found that P-gp overexpression in AML is correlated with a low remission rate. ${ }^{2-7}$ However, whether the presence of LRP influences the response to induction chemotherapy remains controversial. ${ }^{8-11}$ Our previous study showed that the co-existence of LRP and P-gp significantly decreases the effectiveness of induction chemotherapy whereas the isolated presence of LRP or P-gp does not. ${ }^{7}$ Scheper et al. ${ }^{12}$ identified LRP as a drug resistance-associated protein in a P-gp-negative multidrug-resistant lung carcinoma cell line. LRP is the human major vault protein; vaults are localized in nuclear pore complexes and are involved in nucleocytoplasmic transport. Nuclear pore complexes are multicomponent structures that allow bidirectional nucleocytoplasmic exchanges of molecules and particles. ${ }^{13}$ A decrease in the nucleus/cytoplasm ratio of doxorubicin content has been demonstrated in an LRP positive non-small cell lung cancer cell line. ${ }^{14}$ No pharmacological study for LRP has been reported. Therefore, in the present study, we investigated the effects that the presence of LRP has on daunorubicin (DNR) content in the nuclei of leukemic blast cells. We also assessed whether LRP and P-gp affect the response to induction chemotherapy in AML patients.

\section{Materials and Methods}

\section{Patients}

The study cohort was made up of 151 previously untreated AML patients, including 138 patients with de novo AML and 13 patients with overt leukemia transformed from myelodysplastic syndrome (MDS). All patients provided written informed consent for induction chemotherapy. The leukemic subtypes of
Correspondence: Toshiko Motoji, Department of Hematology, Tokyo Women's Medical University, 8-1, Kawada-cho, Shinjuku-ku, Tokyo 162-8666, Japan.

Tel.+81.333538111 - Fax:+81.352697329.

E-mail: motoji@dh.twmu.ac.jp

Key words: lung resistance-related protein, P-glycoprotein, reversing agent, acute myelogenous leukemia.

Acknowledgments: we thank Dr A. Takeshita, Dr K. Nishikawa, Dr T. Sai, Dr N. Asou, Dr S. Ohtake, Dr N. Saburi, Dr S. Kageyama, and Dr M. Imamura. We also express our gratitude to all members of the Japan Adult Leukemia Study Group.

Received for publication: 18 January 2012.

Revision received: 10 July 2012.

Accepted for publication: 10 September 2012.

This work is licensed under a Creative Commons Attribution NonCommercial 3.0 License (CC BYNC 3.0).

(C) Copyright K. Tsuji et al., 2012

Licensee PAGEPress, Italy

Hematology Reports 2012; 4:e18

doi:10.4081/hr.2012.e18

de novo AML were determined according to the French-American-British classification as follows: ${ }^{15} 2,34,57,19,23$, and 3 cases of M0, M1, M2, M4, M5, and M6, respectively. Patient age ranged from 16 to 84 years (mean 49 years). The immunophenotype (CD34 and CD7) of blast cells was examined with a flow cytometer and defined as positive when more than $20 \%$ of the blasts were stained. Cytogenetic analysis was performed using the Q-banding method and assessed according to International system for human cytogenetic nomenclature guidelines. ${ }^{16}$ Chromosomal abnormalities were classified into three categories according to the report by Slovak et al. ${ }^{17}$ The favorable risk category included patients with abnormalities of $\operatorname{inv}(16) / t(16 ; 16) / \operatorname{del}(16 q)$ or $(15 ; 17)$ with any additional abnormalities, or $\mathrm{t}(8 ; 21)$ without either a $\operatorname{del}(9 q)$ or a complex karyotype. The intermediate risk category included patients characterized by $+8,-\mathrm{Y},+6$, del $(12 \mathrm{p})$, or a normal karyotype. The unfavorable risk category was defined by the presence of one or more of $-5 / \operatorname{del}(5 q),-7 / \operatorname{del}(7 q)$, inv(3q), abnormalities $11 \mathrm{q}, 20 \mathrm{q}$ or $21 \mathrm{q}$, $\operatorname{del}(9 \mathrm{q}), \mathrm{t}(6 ; 9)$, $\mathrm{t}(9 ; 22)$, abnormalities $17 \mathrm{p}$, and a complex karyotype defined as 3 or more abnormalities.

\section{Chemotherapy}

For de novo AML patients and patients with overt leukemia transformed from MDS, three regimens were used. Thirty-nine de novo AML patients and 2 patients with overt leukemia 
transformed from MDS were treated with behenoylcytarabine, DNR, and 6-mercaptopurine according to the Japan Adult Leukemia Study Group (JALSG) AML92 protocol. ${ }^{18}$ Ninety-six de novo AML patients and 8 patients with overt leukemia transformed from MDS were treated with idarubicin and arabinosylcytosine according to the JALSG AML95 and MDS protocols. ${ }^{19-20}$ The remaining 3 de novo AML patients and 3 patients with overt leukemia transformed from MDS were treated according to the CAG protocol. ${ }^{21}$ The response to treatment was assessed after one course of induction therapy. Complete remission (CR) was defined as the achievement of a morphologically normal marrow, a granulocyte count of $1.5 \times 10^{3} / \mathrm{L}$ or over, and a platelet count of $100 \times 10^{9} / \mathrm{L}$ or over. Remission failure was defined according to the classification proposed by Preisler. ${ }^{22}$ Relapse was defined as the presence of more than $5 \%$ blasts in marrow aspirates or development of extra-medullary leukemia in patients with previously documented CR after one course of induction chemotherapy according to National Cancer Institute criteria. ${ }^{23}$

\section{Separation of leukemic blast cells}

Mononuclear cells were separated through Ficoll-Conray (specific gravity: 1.077) density gradient centrifugation from bone marrow or peripheral blood taken at the initial diagnosis. The leukemic blast cells thus prepared were either used immediately or cryopreserved in liquid nitrogen with $10 \%$ dimethylsulphoxide and $50 \%$ fetal calf serum (FCS; Intergen, Purchase, NY, USA) until used as previously described. ${ }^{7}$ The presence of more than $80 \%$ leukemic blast cells in each sample was confirmed by cytospin preparation.

\section{Detection of lung resistance-related protein and P-glycoprotein expres- sion on leukemic blast cells}

The avidin-biotin-glucose oxidase method was carried out on the cytospin preparations. The slides were fixed with paraformaldehyde and incubated with 10\% normal rabbit serum (Nichirei, Tokyo, Japan) in order to block nonspecific reactions, and stained with a monoclonal antibody (mAb) against LRP (LRP56, Nichirei) as previously described. ${ }^{7}$ Positivity was classified according to the positive percentage as reported previously: negative (-); less than $10 \%$, positive $(+)$; and more than $10 \%$ positive $(++)$.

P-gp expression was detected by indirect immunofluorescence staining by using MRK16 mAb (Kyowa Medix, Tokyo, Japan) as previously reported. ${ }^{6}$ Positivity was classified according to our previous report as follows: less than $20 \%$ $(-)$ and more than $20 \%(+)$. No difference was observed in the P-gp positivity between fresh and cryopreserved samples.

\section{Isolation of nuclei}

Nuclei were isolated as described by Newmeyer et al. ${ }^{24}$ Leukemic blast cells were suspended in reticulocyte standard buffer (RSB; $\mathrm{NaCl} 0.01 \mathrm{M}, \mathrm{MgCl}_{2} 0.0015 \mathrm{M}$, Tris-HCl $0.01 \mathrm{M}, \mathrm{pH} 7.4$ ) and centrifuged for $5 \mathrm{~min}$ at $2000 \mathrm{rpm}$. The cells were incubated in RSB with 10\% Nonidet P40 (Sigma, St. Louis, M0, USA), and then centrifuged for $1 \mathrm{~h}$ at $40,000 \mathrm{~g}$. The nuclei that formed a sediment were resuspended in solution A (sucrose $250 \mathrm{mM}$, Dithiothreitol $1 \mathrm{mM}, 1 \times$ buffer A salts, spermidine $0.5 \mathrm{mM}$, spermine $0.2 \mathrm{mM}$, and phenylmethylsulfonyl fluoride $1 \mathrm{mM}$ ).

\section{Accumulation of $\left[{ }^{3} \mathrm{H}\right]$ daunorubicin in isolated nuclei}

The accumulation of $1 \mathrm{M}\left[{ }^{3} \mathrm{H}\right]$ DNR (18.5 $\mathrm{Ci} / \mathrm{mmol}$; Perkin Elmer Life Sciences, Boston, MA, USA) in isolated nuclei was studied as described by Kitazono et al. ${ }^{25}$ The isolated nuclei suspended in solution A were incubated with $1 \mathrm{M} \mathrm{DNR}$ for $10 \mathrm{~min}$ at $37^{\circ} \mathrm{C}$ in the presence or absence of $100 \mathrm{~g} / \mathrm{mL}$ mAb LRP56 (Kamiyama Biomedical, Seattle, WA, USA) or 3 M PAK-104P\{2-[4-(diphenylmethyl)-1-piperazinyl ] ethyl-5-(trans-4,6-dimethyl-1,3,2dioxaphosphorinan-2-yl)-2,6-dimethyl-4-(3nitrophenyl)-3-pyridinecarboxylate P-oxide as an LRP reversing reagent. ${ }^{26}$ The PAK-104P was a gift from Dr S. Akiyama (Cancer Research, Kagoshima University, Japan). The nuclei were suspended in aqueous counting scintillant (Amersham Biosciences, Buckinghamshire, UK), and the radioactivity in the nuclei of $1 \times 10^{4}$ cells was determined by a liquid scintillation counter system (LSC-700; Aloka, Tokyo, Japan).

\section{Statistical analysis}

The relationships of LRP and P-gp expression with the response to induction chemotherapy, and with the clinical parame-

Table 1. Lung resistance-related protein and P-glycoprotein expression in acute myelogenous leukemia patients.

\begin{tabular}{lcccc} 
AMll subtype & \multicolumn{2}{c}{ LRP positive } & \multicolumn{2}{c}{ P-gip positive } \\
& n & $\%$ & n & $\%$ \\
M0 & $0 / 2$ & 0 & $1 / 2$ & 50 \\
M1 & $16 / 34$ & 47.1 & $13 / 34$ & 38.2 \\
\hline M2 & $27 / 57$ & 47.4 & $29 / 57$ & 50.9 \\
M4 & $9 / 19$ & 47.4 & $4 / 19$ & 21.2 \\
\hline M5 & $12 / 23$ & 52.2 & $8 / 23$ & 34.8 \\
M6 & $1 / 3$ & 33.3 & $0 / 3$ & 0 \\
\hline Subtotal & $65 / 138$ & 47.1 & $55 / 138$ & 39.9 \\
Overt leukemia & $7 / 13$ & 53.8 & $9 / 13$ & 69.2 \\
transformed from MDS & & & & 42.4 \\
\hline Total & $72 / 151$ & 47.7 & $64 / 151$ & \\
\hline AML, acute myelogenous leukemia; LRP, lung resistance-related protein; P-gp, P-glycoprotein; MDS, myelodysplastic syndrome.
\end{tabular}

ters such as age, subtype (i.e. AML and MDS), WBC count, immunophenotype (i.e. CD34 and CD7), LD, chromosome abnormalities were assessed by the $\chi^{2}$ test. The relationship between LRP expression and DNR accumulation in isolated nuclei was evaluated by a twosided t-test. Univariate logistic regression analysis was conducted to calculate crude odds ratios (ORs) and 95\% confidence intervals (CIs). Furthermore, we used stepwise multivariate logistical regression analysis to calculate adjusted ORs and 95\% CIs and to account for other confounding factors. All statistical analyses were performed by SAS software (Version 9.1.3 (TS1M3), SAS Institute Inc., Cary, NC, USA).

\section{Results}

Lung resistance-related protein and $\mathrm{P}$-glycoprotein expression in acute myelogenous leukemia patients

LRP and P-gp expression of in AML patients is summarized in Table 1 . The frequency of LRP positivity was $47.7 \%$ (72 of 151). There were no significant differences in the expressions of these proteins between de novo AML patients $(47.1 \%, 65$ of 138$)$ and patients with overt leukemia transformed from MDS (53.8\%, 7 of 13). The overall proportion of P-gp positive samples was $42.4 \%$ (64 of 151); this was found to be significantly higher in patients with overt leukemia transformed from MDS $(69.2 \%, 9$ of 13) than that in de novo AML patients $(39.9 \%$, 55 of 138) ( $\mathrm{P}=0.041)$. While there were no correlations between LRP and clinical parameters, the expression of P-gp was found to be frequently positive when expression of $\mathrm{CD} 7$ or CD34 was positive (CD7, $\mathrm{P}=0.016$; CD34, $\mathrm{P}=0.006)$. In addition, P-gp expression was found to be frequently negative when the 
white blood cell (WBC) count exceeded 50,000 $(\mathrm{P}=0.014)$. There was a negative correlation between percentage of P-gp cells and WBC count $(\mathrm{r}=-0.207, \mathrm{P}=0.011)$.

Lung resistance-related protein and P-glycoprotein overexpression, clinical parameters, and the response to induction chemotherapy

The overall CR rate was $67.5 \%$ (102 of 151 patients); the failure rate of induction chemotherapy was $32.5 \%$ (49 of 151 patients). Patients were classified according to Preisler's classification: ${ }^{22} 24$ patients had hypocellular marrow at any time during chemotherapy (type I), 10 achieved hypocellular marrow but leukemic cells regrew within four weeks (type II), one survived for more than four weeks with hypocellular marrow (type III), 2 died with hypocellular marrow without evidence of residual leukemia (type IV), and 12 patients could not be typed. Of these 49 patients, the leukemic blast cells of 22 (44.9\%) were LRP/Pgp double positive. As shown in Table 2, the CR rate of LRP positive patients $(56.9 \%, 41$ of 72$)$ was significantly lower than that of LRP negative patients $(77.2 \%, 61$ of 79$)(\mathrm{P}=0.0079)$. The CR rate of P-gp positive patients (54.7\%, 35 of 64) was also significantly lower than that of Pgp negative patients $(77.0 \%, 67$ of 87$)$

Table 2. Risk factors which affect inferior complete remission rates.

\begin{tabular}{|c|c|c|c|c|}
\hline & & ivariat & ris & \\
\hline & CR rates & $\chi^{2}$ & Logistic r & nalysis \\
\hline & & & Odds ratio & $95 \% \mathrm{CI}$ \\
\hline LRP+ vs LRP- & $56.7 \%$ vs $77.2 \%$ & 0.0079 & 0.390 & $0.193-0.788$ \\
\hline Pgp+ vs P-gp- & $54.5 \%$ vs $77.0 \%$ & 0.0038 & 0.360 & $0.179-0.726$ \\
\hline LRP+/Pgp+ vs others & $38.0 \%$ vs $76.5 \%$ & 0.0005 & 0.307 & $0.131-0.72$ \\
\hline $\begin{array}{l}\text { Chromosomal abn } \\
\text { unfavourable } v s \text { good + } \\
\text { intermediate }\end{array}$ & $33.3 \%$ vs $68.8 \%$ & 0.0296 & 0.227 & $0.054-0.954$ \\
\hline
\end{tabular}

$\mathrm{CI}$, confidence interval; CR, complete remission; LRP, lung resistance-related protein; P-gp, P-glycoprotein.

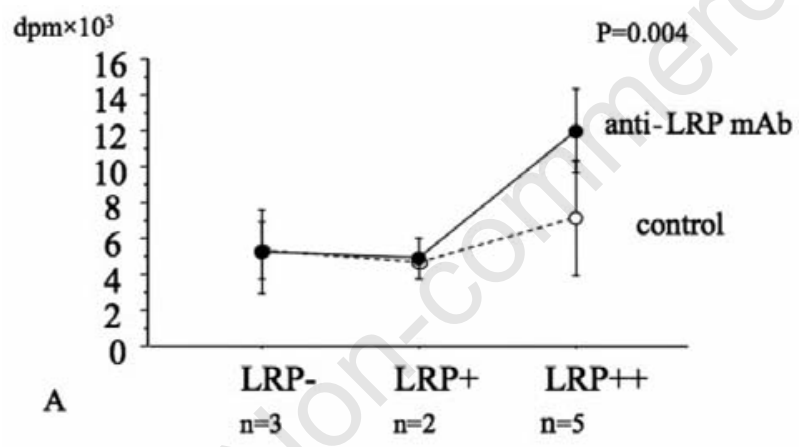

dpm $\times 10^{3}$

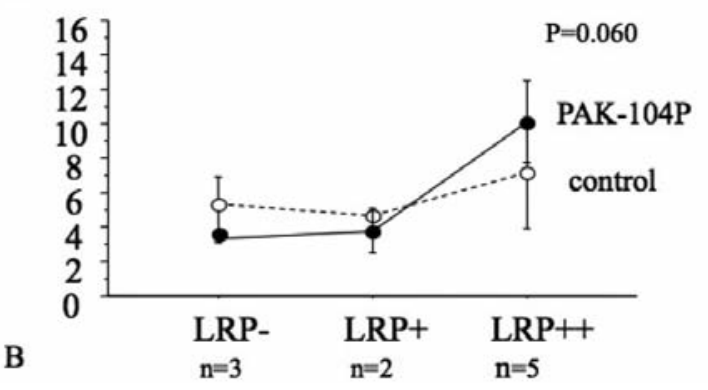

Figure 1. DNR accumulation in isolated nuclei and effects of the addition of $(A)$ antiLRP $m A b$ and (B) PAK-104P. A) DNR accumulation with the addition of anti-LRP $m A b$ increased significantly when the leukemic blast cells were $\mathrm{LRP}++(\mathrm{P}=0.004)$; B) PAK$104 \mathrm{P}$ increased DNR accumulation when the samples were $\mathrm{LRP}++$, with marginal significance $(P=0.06)$. Open circles $(O)$ indicate the untreated controls; closed circles $(\bullet)$ indicate the presence of anti-LRP $m A b$ or PAK-104P. Data are expressed as the mean $\pm S D$ of triplicate results.

$(\mathrm{P}=0.0038)$. The $\mathrm{CR}$ rate of LRP/P-gp double positive patients $(38.9 \%, 14$ of 36$)$ was significantly lower than that of other groups $(\mathrm{P}=0.0005)$. Univariate logistical regression analysis (Table 2 ) revealed that the crude ORs for CR were 0.390 (95\% CI: $0.193-0.788)$ for LRP positivity, 0.360 (95\% CI: 0.179-0.726) for P-gp positivity, and 0.307 (95\% CI: 0.131-0.720) for LRP/P-gp double positivity. After adjusting for the confounding factors using the stepwise multivariate logistical regression analysis, the presence of LRP/P-gp double positivity and Pgp positivity were found to be independent prognostic factors; ORs were 0.233 (95\% CI: $0.103-0.529)$ and 0.393 (95\% CI: 0.188-0.820), respectively.

Regarding the relationships between the CR rate and various clinical parameters, the $\mathrm{CR}$ rate of patients with unfavorable chromosomal abnormalities was significantly lower than that of patients with favorable and intermediate chromosomal abnormalities (33.3\% vs $68.8 \%, \mathrm{P}=0.0296)$. The $\mathrm{OR}$ of $\mathrm{CR}$ was 0.227 (95\% CI: $0.054-0.954)$ by univariate logistical regression analysis. There were no significant differences with respect to $\mathrm{CR}$ regarding other clinical parameters.

\section{Functional assay of lung resistance-} related protein expression

Figure 1 shows the differences in DNR accumulation with respect to LRP positivity with and without anti-LRP mAb or PAK-104P. AntiLRP mAb significantly increased DNR accumulation when the samples were LRP++ $(\mathrm{P}=0.004)$. PAK-104P also increased DNR accumulation when the samples were LRP++, with marginal significance $(\mathrm{P}=0.060)$. These results indicate that anti-LRP $\mathrm{mAb}$ and PAK104P increase DNR accumulation in leukemic cells that highly express LRP.

\section{Discussion}

The $L R P$ gene is located on chromosome 16 , proximal to the multidrug resistance-associated protein gene. It encodes a nuclear major vault protein homolog that may disrupt the transport of drugs from the cytoplasm to the nucleus. ${ }^{13}$ In this study, we demonstrated that the addition of an mAb against LRP or PAK104P increases DNR accumulation in isolated nuclei. DNR accumulation in the nuclei was higher when the cells highly expressed LRP. Our results agree with those of a previous report demonstrating that a polyclonal antibody against LRP in adult T-cell leukemia enhances doxorubicin efflux in isolated nuclei. ${ }^{27}$ Furthermore, the addition of verapamil is reported to partially restore the doxorubicin nucleus/cytoplasm ratio in non-small cell lung cancer cell line. ${ }^{14}$ This indicates that the inhi- 
bition of LRP function may lead to an increase in DNR accumulation in nuclei, thus increasing the effectiveness of the treatment. In the present study, we evaluated whether the presence of LRP, P-gp alone or the co-existence of LRP and P-gp in leukemic blast cells influences the response of AML patients to induction chemotherapy. The $\mathrm{CR}$ rate was not only significantly lower in LRP/P-gp double positive patients, but also lower in only LRP or P-gp positive patients. Furthermore, multivariate analysis confirmed a significantly lower CR rate in LRP/P-gp double positive patients. Therefore, the presence of both LRP and P-gp may be a sufficiently strong factor for predicting the response to induction chemotherapy. In our previous report, the presence of LRP or P-gp alone was not powerful enough to predict the effectiveness of induction chemotherapy. ${ }^{7}$ Compared to our previous research, a greater number of AML patients were examined in the present study, and analyzed cases were limited to AML, except M3. These different conclusions may be due to differences in patient populations. As for clinical parameters, only chromosomal abnormalities influenced the CR rate.

\section{Conclusions}

The present results indicate that the presence of LRP and/or P-gp in leukemic blast cells may be risk factors for resistance to induction chemotherapy. As our data demonstrate that high LRP levels obstruct the transport of DNR into the nucleus, trials inhibiting LRP function, similar to the inhibition of P-gp, are necessary to potentially improve the clinical response.

\section{References}

1. See YP, Carlsen SA, Till JE, et al. Increased drug permeability in Chinese hamster ovary cells in the presence of cyanide. Biochim Biophys Acta 1974;373:242-52.

2. Campos L, Guyotat D, Archimbaud E, et al. Clinical significance of multidrug resistance P-glycoprotein expression on acute non-lymphoblastic leukemia cells at diagnosis. Blood 1992;79:473-6.

3. Del Poeta G, Stasi R, Aronica G, et al. Clinical relevance of P-glycoprotein expression in de novo acute leukemia. Blood 1996;87:1997-2004.

4. Michieli M, Damiani D, Germin A, et al. Overexpression of multidrug resistance associated p-170- glycoprotein in acute non-lymphocytic leukemia. Eur J Haematol 1992;48:87-92.

5. Hunault M, Zhou D, Delmer, A, et al.
Multidrug resistance gene expression in acute myeloid leukemia: major prognosis significance for in vivo drug resistance to induction treatment. Ann Hematol 1997;74:65-71.

6. Wang $\mathrm{YH}$, Motoji T, Motomura S, et al. Recovery of drug resistance-reversing agent on acute myelogenous leukemic blasts and K562 cells resistant to adriamycin cell line. Eur J Haematol 1997;58: 186-94.

7. Tsuji K, Motoji T, Sugawara I, et al. Significance of lung resistance-related protein in the clinical outcome of acute leukaemic patients with reference to $\mathrm{P}$ glycoprotein. Br J Haematol 2000;110:3708.

8. Legrand 0, Simonin G, Zittoun R, et al. Lung resistance protein (LRP) gene expression in adult acute myeloid leukemia: a critical evaluation by three techniques. Leukemia 1998;12:1367-74.

9. Michieli M, Damiani D, Ermacora A, et al. P-glycoprotein, lung resistance-related and multidrug resistance associated protein in de novo acute non-lymphocytic leukaemias: biological and clinical implications. Br J Haematol 1999;104:328-35.

10. Leith CP, Kopecky KJ, Chen IM, et al. Frequency and clinical significance of the expression of multidrug resistance proteins MDR1/P-glycoprotein, MRP1, and LRP in AML. A southwest oncology group study. Blood 1999;94:1086-99.

11. Tsimberidou AM, Paterakis G, Androutsos $\mathrm{G}$, et al. Evaluation of the clinical relevance of the expression and function of $P$ glycoprotein, multidrug resistance protein and lung resistance protein in patients with primary acute myelogenous leukemia. Leuk Res 2002;26:143-54.

12. Scheper RJ, Broxterman HJ, Scheffer GL, et al. Overexpression of a M(r)110,000 vesicular protein in non-P-glycoproteinmediated multidrug resistance. Cancer Res 1993;53:1475-9.

13. Scheffer GL, Wijngaard PLJ, Flens MJ, et al. The drug resistance-related protein LRP in the human major vault protein. Nat Med 1995;1:578-82.

14. Schuurhuis GJ, Broxterman HJ, de Lange JHM, et al. Early multidrug-resistance, defined by changes in intracellular doxorubicin distribution, independent of $\mathrm{P}$ glycoprotein. Br J Cancer 1991;64:857-61.

15. Bennett JM, Catovsky D, Daniel MT, et al. Proposals for the classification of acute myeloid leukemia. A report of the FrenchAmerican-British cooperative group. Ann Int Med 1985;103:626-9.

16. ISCN. Guidelines for Cancer Cytogenetics. In: An international system for human cytogenetic nomenclature. Basel, Switzer- land: Karger; 1995.

17. Slovak ML, Kopecky KJ, Cassileth PA, et al. Karyotypic analysis predicts outcome of preremission and postremission therapy in adult acute myeloid leukemia: a southwest oncology group/eastern cooperative oncology group study. Blood 2000;96:407583.

18. Miyawaki S, Tanitomo M, Kobayashi T, et al. No beneficial effect from addition of etoposide to daunorubicin, cytarabin, and 6-mercaptopurine in individualized induction therapy of adult acute myeloid leukemia: the JALSG-AML92 study. Int J Hematol 1999;70:97-104.

19. Ohtake S, Miyawaki S, Kiyoi H, et al. Randomised trial of response-oriented individualized versus fixed-schedule induction chemotherapy with idarubicin and cytarabine in adult acute myeloid leukemia: the JALSG AML95 study. Int $\mathrm{J}$ Hematol 2010;91:276-83.

20. Okamoto T, Kanamaru A, Shimazaki C, et al. Combination chemotherapy with risk factor-adjusted dose attenuation for highrisk myelodysplastic syndrome and resulting leukemia in the multicenter study of the Japan Adult Leukemia Study Group (JALSG): results of an interim Analysis. Int J Hematol 2000;72:200-5.

21. Yamada K, Furusawa S, Saito K, et al. Concurrent use of granulocyte colonystimulating factor with low-dose cytosine arabinoside and aclarubicin for previously treated acute myelogenous leukemia: a pilot study. Leukemia 1995;9:10-4.

22. Preisler HD. Failure of remission induction in acute myelocytic leukemia. Med Ped Oncol 1978;4:275-6.

23. Chenson BD, Cassileth PA, Head DR, et al. Report of the National Cancer Institutesponsored workshop on definitions of diagnosis and response in acute myeloid leukemia. J Clin Oncol 1990;8:813-9.

24. Newmeyer DD, Wilson KL. Egg extracts for nuclear import and nuclear assembly reactions. Method Cell Biol 1991;36:607-34.

25. Kitazono M, Sumizawa T, Takebayashi Y, et al. Multidrug resistance and the lung resistance-related protein in human colon carcinoma SW-620 cells. J Natl Cancer Inst 1999;91:1647-53.

26. Shudo N, Mizoguchi T, Kiyosue T, et al. Two pyridine analogues with more effective ability to reverse multidrug resistance and with lower calcium channel blocking activity than their dihydropyridine counterparts. Cancer Res 1990;50:3055-61.

27. Ohno N, Tani A, Uozumi K, et al. Expression of functional lung resistance-related protein predicts poor outcome in adult T-cell leukemia. Blood 2001;98:1160-5. 